\title{
Measurement of resistant starch in vitro and in vivo
}

\author{
BY HANS N. ENGLYST, SUSAN M. KINGMAN, GEOFFREY J. HUDSON \\ AND JOHN H. CUMMINGS
}

MRC Dunn Clinical Nutrition Centre, Hills Road, Cambridge CB2 $2 D H$

(Received 22 November 1994 - Revised 23 June 1995 - Accepted 16 August 1995)

\begin{abstract}
The digestibility of the starch in plant foods is highly variable, and is dependent on a number of factors, including the physical structure of both the starch and the food matrix. An in vitro technique has been developed to categorize starch in plant foods according to its likely rate and extent of digestion in the human small intestine. The in vitro method provides values for rapidly digestible starch, slowly digestible starch and resistant starch (RS). In the present study values for the RS content of foods, as measured by the analytical technique, were compared with the recovery of starch from these foods when fed to healthy ileostomates. Nine ileostomy subjects were given a polysaccharide-free diet with a breakfast supplement, on each of $2 \mathrm{~d}$ (two subjects) or $3 \mathrm{~d}$ (seven subjects), of biscuits made from wheat, potato or banana flours or from moist-heat-processed wheat or maize flours. RS intakes measured in vitro ranged from 8.5 to $15.0 \mathrm{~g} / \mathrm{d}$ for the test biscuits, and mean starch recoveries in ileostomy effluent were 100.4 ( $n$ 5, range 91-106) \% of those values, but there was substantial variation between individuals. It is proposed that $R S$ is defined as 'the sum of starch and starch-degradation products that, on average, reach the human large intestine'. The analytical method for the measurement of RS in vitro based on this definition is shown to provide an accurate prediction of the average amount of starch that is likely to escape complete digestion and absorption in the human small intestine.
\end{abstract}

Resistant starch: Пleostomy: Human small intestine

In 1982 we reported that a fraction of starch in cooled, cooked foods was highly resistant to digestion by pancreatic amylase (EC 3.2.1.1) in vitro, and used the term resistant starch (RS) to describe this fraction (Englyst et al. 1982). Following a series of studies in healthy ileostomy subjects, who were used as a model for digestion in the small intestine (Englyst \& Cummings, 1985, 1986, 1987), it became clear that this type of starch represented only a proportion of the starch that can resist digestion in the human small intestine. Starch that is trapped within whole plant cells or within the food matrix, and some starch granules that have not been fully gelatinized, are hydrolysed only very slowly by $\alpha$-amylase and therefore may escape complete digestion in the small intestine. We therefore extended the term and modified the analytical procedure to include these sources, i.e. the definition of RS and its measurement in vitro were enlarged to include starch and starch-degradation products (Englyst \& Cummings, 1987; Englyst \& Kingman, 1990; Englyst et al. 1992a). The material included in the definition of RS reaches the human large intestine and thus becomes a substrate for microbial fermentation. The end-products are $\mathrm{H}_{2}$ and $\mathrm{CO}_{2}, \mathrm{CH}_{4}$ in about half the population, and short-chain fatty acids, which are absorbed and utilized. However, the energy yield to the body from this source is less than that provided if starch is digested and absorbed in the small intestine. The high levels of butyrate produced from the fermentation of starch may be of benefit to health (Rombeau et al. 1990; Cummings, 1995). It is important, therefore, to be able to predict the amount of starch in foods that is likely to reach the human large intestine. 
Table 1. A nutritional classification of starch

\begin{tabular}{lll}
\hline \hline \multicolumn{1}{c}{ Type of starch } & \multicolumn{1}{c}{ Examples of occurrence } & $\begin{array}{l}\text { Probable digestion in } \\
\text { human small intestine }\end{array}$ \\
\hline $\begin{array}{l}\text { Rapidly digestible starch (RDS) } \\
\text { Slowly digestible starch (SDS) }\end{array}$ & $\begin{array}{l}\text { Freshly cooked starchy food } \\
\text { Resistant starch (RS) }\end{array}$ & $\begin{array}{l}\text { Rapid, complete } \\
\text { Slow but complete }\end{array}$ \\
$\begin{array}{ll}\text { 1. Physically inaccessible starch } \\
\text { 2. Resistant starch granules }\end{array}$ & $\begin{array}{l}\text { Partly milled grains and seeds } \\
\text { 3. Retrograded starch }\end{array}$ & $\begin{array}{l}\text { Resistant } \\
\text { Cooled cooked potato, bread, } \\
\text { Kellogg's Cornflakes }\end{array}$ \\
\hline
\end{tabular}

Fractions of starch with different susceptibilities to digestion should be classified in terms that can be translated into analytical measurements (see Table 1). What is needed are measurements that will characterize starchy foods in terms that reflect the rate and extent of starch digestion in the human gut. Because of the variation between individuals in the rate and extent of starch digestion that is seen in human studies, measurements in vitro will, in practice, be based on the mean of the values observed in vivo. Any definition of RS, or other starch fractions, that is not based on such mean digestibility values cannot serve as the basis for an in vitro analytical procedure. We therefore propose that RS is defined as 'the sum of starch and starch-degradation products that, on average, reach the human large intestine'. The measurement of RS in vitro described by Englyst et al. (1992a) was designed to yield values in agreement with the amounts of starch escaping digestion in the small intestine in studies using ileostomy subjects (Englyst \& Cummings, 1985, 1986, 1987; Englyst \& Kingman, 1990). The aim of the present study was to validate further the technique for the measurement of RS, using ileostomy subjects as a model for digestion in the small intestine. The test foods in this study have been used, also, to determine the fate of starch reaching the large intestine of subjects with an intact gut.

\section{SUBJECTS AND METHODS}

\section{Subjects}

Nine healthy ileostomy subjects (seven female, two male), mean age $45 \cdot 7$ (range 34-59) years took part in the studies. All the subjects had had total colectomies for ulcerative colitis, mean 16.7 (range 5-27) years before the studies. As far as could be ascertained the maximum amount of ileum resected in any subject was $0.3 \mathrm{~m}$; most operation notes recorded only minimal ileal resection. The subjects' average height was 1.67 (range $1.52-1.80$ ) $\mathrm{m}$ and weight 73 (range 63.6-89) kg. All were well apart from one, who was diabetic and taking appropriate oral therapy.

\section{Recruitment}

Subjects were recruited from the membership of the Ileostomy Association of Great Britain by an appeal in the Association's magazine and at the annual national conference. Medical information was obtained from prospective volunteers by questionnaires and, where possible, from the hospital that had cared for the subject during the time of ulcerative colitis surgery.

Ethical approval for these studies was obtained from the MRC Dunn Clinical Ethical Committee. 
Table 2. Composition of the test biscuits

\begin{tabular}{lcccc}
\hline Biscuit & $\begin{array}{c}\text { White wheat } \\
\text { flour }(\mathrm{g})\end{array}$ & $\begin{array}{c}\text { Test starch } \\
\text { (g) }\end{array}$ & $\begin{array}{c}\text { Margarine } \\
\text { (g) }\end{array}$ & $\begin{array}{c}\text { Icing sugar } \\
\text { (g) }\end{array}$ \\
\hline Wheat & 75 & 75 & 75 & 18 \\
Potato & 75 & 75 & 75 & 18 \\
Banana & 75 & 75 & 75 & 18 \\
Maize-RS & 75 & 75 & 100 & 18 \\
Wheat-RS & - & 128 & 100 & 13 \\
\hline
\end{tabular}

RS, resistant starch.

\section{Protocol}

Subjects lived in the metabolic suite at the Dunn Clinical Nutrition Centre, Cambridge, during their participation in the study. For the purpose of pooling the collected ileal effluent, the study was divided into consecutive $24 \mathrm{~h}$ periods, starting at 09.00 hours each day. Commencing at $\mathbf{1 2 . 0 0}$ hours on the day before and throughout the study, subjects ate a plant-polysaccharide-free diet. At random, one day was assigned for each subject to receive only the polysaccharide-free diet and a supplement of $100 \mathrm{~g}$ fudge (made from sugar, butter and water) to provide the same energy intake on all days. On two other days (two subjects) or three other days (seven subjects), each subject received, in random order, one of the five test materials in the form of a biscuit as a supplement to breakfast at 09.00 hours. Subjects were taken into the study until each type of biscuit had been eaten on five test days.

\section{Diet}

The basal diet was prepared in the diet kitchen of the Dunn Clinical Nutrition Centre, and included meat, cheese, prawns, salmon, eggs, mayonnaise, jelly, cream, sugar, milk and tea or coffee. The diet provided the following (per d): energy, $7 \mathrm{MJ}$; protein, $123 \mathrm{~g}$; fat, $107 \mathrm{~g}$; carbohydrate, $45 \mathrm{~g}$. Analysis of this diet showed it to contain less than $1 \%$ substances measuring as NSP or starch.

At 09.00 hours on test days, in addition to the plant-polysaccharide-free breakfast (bacon, egg and tea or coffee with milk), subjects were given $100 \mathrm{~g}$ of biscuits made to the recipes given in Table 2.

The test starch in the wheat biscuits (containing rapidly and slowly digestible starch forms) was gluten-free wheat starch. Potato flour (containing $\mathbf{R S}_{2}$ ) was obtained commercially and banana flour (containing $\mathrm{RS}_{2}$ ) was made from freeze-dried green bananas. The maize-RS biscuits (containing $\mathrm{RS}_{3}$ ) were made with high-amylose maize starch (made to a slurry in water and cooked at $100^{\circ}$ for $1 \mathrm{~h}$, cooled at $5^{\circ}$ overnight and then freeze-dried), and the wheat-RS biscuits (containing $\mathrm{RS}_{3}$ ) were made with freeze-dried wheat starch rendered high in RS by repeated autoclaving and cooling. A sample from each batch of biscuits was retained for analysis.

\section{Effluent collection}

Ileostomy effluent was collected every $2 \mathrm{~h}$ during the day from 07.00 hours until retiring at 23.00 hours. The effluent was emptied from the ileostomy bag into a weighed beaker, frozen rapidly in solid $\mathrm{CO}_{2}$, weighed, and freeze-dried before ball-milling. Dry effluent was pooled into $24 \mathrm{~h}$ periods $(09.00-09.00$ hours). 


\section{Chemical methods}

Total starch and RS in the food samples were measured by the method of Englyst $e t$ al. $(1992 a)$. Starch in the effluents was calculated as the sum of free glucose and that from amyloglucosidase (EC 3.2.1.3)-susceptible glucose polymers (after gelatinization and dispersion with $\mathrm{KOH}$ ), expressed as starch polysaccharides (i.e. glucose $\times 0.9$ ).

NSP in the diet and in the effluent samples were measured by the method of Englyst $e t$ al. $(1992 b)$.

Values for total carbohydrate were obtained following direct Saeman hydrolysis; neutral sugars were measured as alditol acetate derivatives by GLC and uronic acids were measured by colorimetry as described by Englyst et al. (1992b).

\section{RESULTS AND DISCUSSION}

\section{Composition of the test foods}

The starch and NSP contents of the test foods are given in Table 3. Each type of biscuit contained approximately $500 \mathrm{~g}$ starch $/ \mathrm{kg} \mathrm{DM}$, of which between 3 and $150 \mathrm{~g} / \mathrm{kg} \mathrm{DM}$ was measured as RS in vitro. The biscuits made with a mixture of wheat flour and wheat starch contained only $3 \mathrm{~g} \mathrm{RS} / \mathrm{kg}$ DM. Biscuits made with potato flour and with banana flour contained 132 and $150 \mathrm{~g} \mathrm{RS} / \mathrm{kg} \mathrm{DM}$ respectively, which could be dispersed by gelatinization in boiling water and thus shown to be in the form of $\mathrm{RS}_{2}$ (RS granules). Biscuits made with the autoclaved wheat-RS product and the cooked high-amylose maize-RS product both contained $85 \mathrm{~g} \mathrm{RS} / \mathrm{kg}$, which was found to be resistant to pancreatic amylase unless dispersed in $2 \mathrm{M}-\mathrm{KOH}$, and was therefore identified as $\mathbf{R S}_{3}$ (retrograded amylose).

\section{Composition of effluent}

The mean output of effluent by subjects during the polysaccharide-free (control) period was 449 (SEM 86) $\mathrm{g} / \mathrm{d}$. These values and those for the excretion of solids (Table 4) are within the normal range for excretion of effluent by healthy ileostomates (McNeil et al. 1982).

The values obtained during the control period were 2.7 (SEM 0.6) $\mathrm{g} / \mathrm{d}$ for NSP and 0.2 (SEM 0.1$) \mathrm{g} / \mathrm{d}$ for starch. Total carbohydrate excretion during the control period (obtained by direct hydrolysis and measurement of constituent sugars), however, averaged $4 \cdot 0($ SEM $1 \cdot 0) \mathrm{g} / \mathrm{d}$. The difference was largely accounted for as galactose and fucose, probably originating from mucin secretions (Englyst \& Cummings, 1985).

There was no significant difference in the volume of wet effluent excreted by the subjects during any of the dietary periods when assessed by analysis of variance or by paired $t$ test. In contrast, excretion of effluent solids was significantly increased in comparison with the control period $(P<0.001$, paired $t$ test) when the subjects were consuming the RScontaining test biscuits. As was the case for the control period, values for total carbohydrate in the effluents were greater than the sum of NSP and starch.

\section{Recovery of starch in ileostomy effluent}

It is generally assumed that free sugars are rapidly absorbed in the human small intestine and there is little evidence to contradict this, except for the non-absorption of lactose in lactase-deficient subjects (Dahlqvist \& Borgstrom, 1961). It is probable, therefore, that any free glucose present in ileostomy effluent is the result of enzymic hydrolysis of dextrins and starch within the collection bag. Accordingly, starch in the effluents was calculated as the sum of free glucose and amyloglucosidase-susceptible glucose polymers, and expressed as starch polysaccharides (i.e. glucose $\times 0.9$ ). There was wide variation between individual 
Table 3. Composition of test foods

\begin{tabular}{|c|c|c|c|c|}
\hline & \multirow{2}{*}{$\begin{array}{c}\mathrm{DM} \\
(\mathrm{g} / \mathrm{kg})\end{array}$} & \multicolumn{3}{|c|}{ Content (g/kg DM) } \\
\hline & & Total starch & RS & NSP \\
\hline $\begin{array}{l}\text { Fudge } \\
\text { Biscuits }\end{array}$ & 960 & 18 & 0 & 1 \\
\hline Wheat & 967 & 507 & 3 & 17 \\
\hline Potato & 960 & 509 & 132 & 13 \\
\hline Banana & 953 & 470 & 150 & 27 \\
\hline Maize-RS & 971 & 471 & 85 & 11 \\
\hline Wheat-RS & 977 & 472 & 85 & 10 \\
\hline
\end{tabular}

RS, resistant starch.

subjects in the amount of starch digested from a particular product, and the recoveries of starch from the test biscuits ranged from 74 to $126 \%$ of the RS fed (Table 5).

The excretion of total solids, total carbohydrate and NSP were not significantly different (paired $t$ test) from control values when subjects consumed the wheat biscuits containing rapidly and slowly digestible starch.

The potato biscuits contained potato-starch granules (available commercially as a flour). Raw potato-starch granules are highly resistant to hydrolysis by pancreatic $\alpha$-amylase because of the crystal structure prevailing in the granule. The granules are readily digestible if this structure is disrupted by moist heat but dry cooking methods, as used in the preparation of the biscuits, have little effect. The measured amount of RS in the $100 \mathrm{~g}$ of potato biscuits consumed was $13.2 \mathrm{~g}$. The amount of starch recovered in vivo ranged from 12.5 to $15.5 \mathrm{~g} / \mathrm{d}$ (average 104 (SEM $4 \cdot 1,95 \%$ confidence $8 \cdot 1$ ) $\%$ of RS fed).

Banana flour (unripe bananas, dried and powdered), like potato flour, has starch granules that are highly resistant to hydrolysis by pancreatic $\alpha$-amylase. The biscuits made with banana flour provided the greatest quantity of RS $(15.0 \mathrm{~g})$, and a mean of $13.9 \mathrm{~g}$ starch/d was recovered in the ileostomy effluent. As for the potato biscuits, the amount of starch excreted by individuals following consumption of the banana biscuits was variable, and in this case the range was even greater $(11 \cdot 1-16 \cdot 6 \mathrm{~g} / \mathrm{d})$. The average recovery was a little lower, at 91 (SEM $1 \cdot 2,95 \%$ confidence $2 \cdot 4$ ) $\%$ of RS fed.

The maize RS biscuits contained a high-amylose maize starch (Hylon VII; National Starch and Chemical, Beaconsfield, Bucks.) that had been heated with water at $>100^{\circ}$ for $1 \mathrm{~h}$, cooled overnight, drained, freeze-dried and milled. According to measurements in vitro, $100 \mathrm{~g}$ biscuits made with this product provided $8.5 \mathrm{~g}$ RS. Subjects consuming these biscuits excreted variable quantities of starch (mean $8.6 \mathrm{~g} / \mathrm{d}$ ), ranging from 6.4 to $10.4 \mathrm{~g} / \mathrm{d}$. The average recovery was 101 (SEM $9 \cdot 0,95 \%$ confidence $17 \cdot 7$ ) \% of RS fed.

The wheat-RS preparation used in the present study was made from NSP-free wheat starch by repeated autoclaving and cooling, followed by enzymic hydrolysis and removal of some of the digestible fraction. These treatments markedly increased the proportion of $\mathrm{RS}_{3}$ in the product. These biscuits gave results for total starch and RS that were virtually identical with those obtained for the biscuits made with high-amylose maize RS, and a similar recovery of starch in ileostomy effluent was observed (mean $9.0 \mathrm{~g} / \mathrm{d}$ ) ranging from 8.1 to $10 \cdot 7 \mathrm{~g} / \mathrm{d}$. The average recovery was 106 (SEM $5 \cdot 2,95 \%$ confidence $10 \cdot 1$ ) $\%$ of RS fed.

The proportion of starch that reaches the large intestine (as starch or starch-degradation products) is quite variable between individuals. The analytical procedure used here (Englyst 


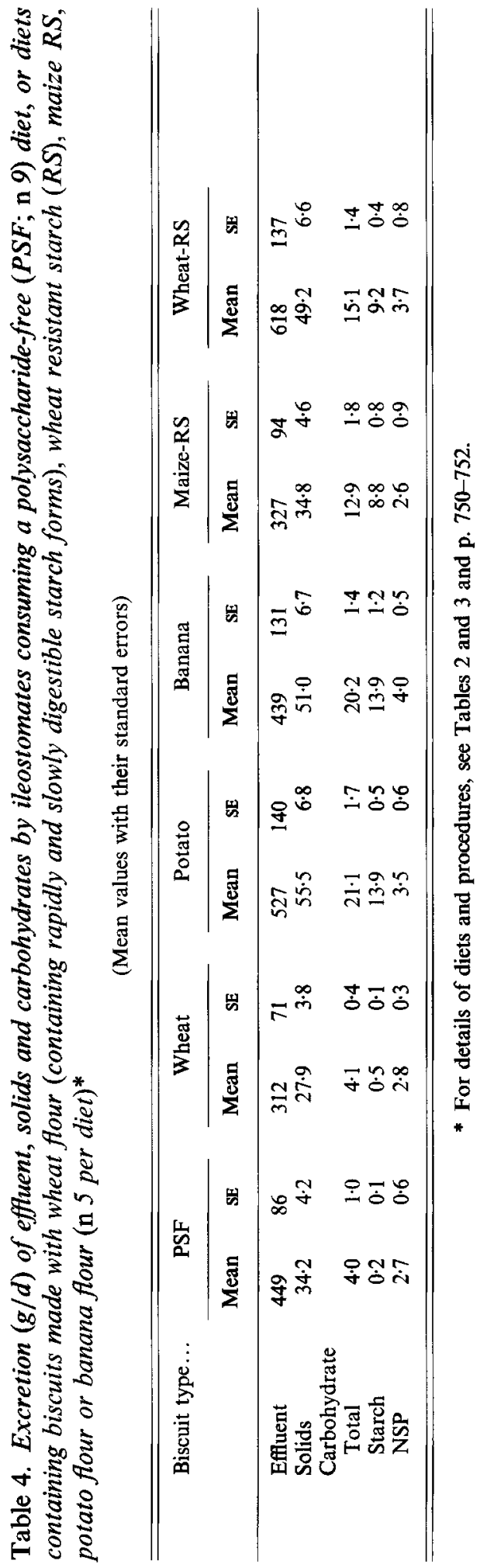


Table 5. The amounts of resistant starch $(R S)$ fed and starch recovered, corrected for starch recovered on the polysaccharide-free ( $P S F)$ day, from healthy ileostomates (n 5 in all cases)*

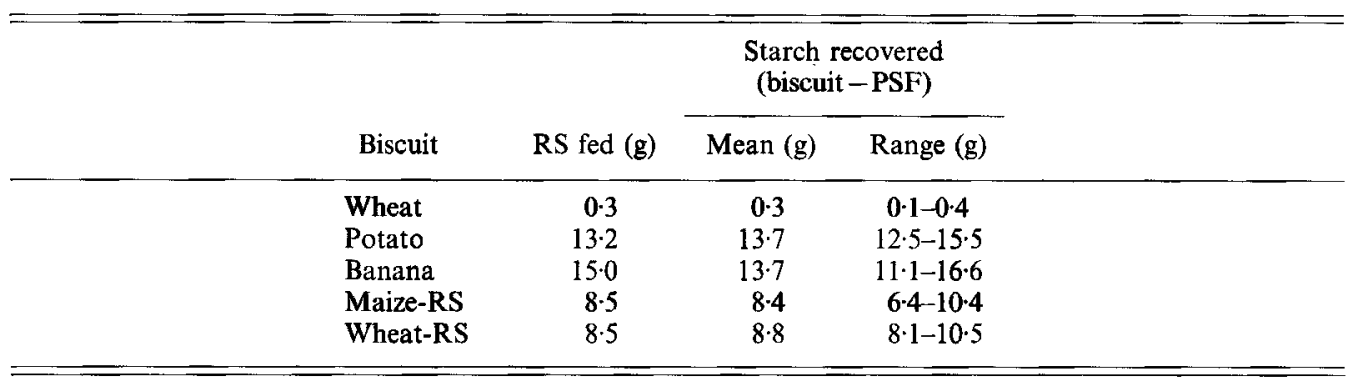

* For details of diets and procedures, see Tables 2 and 3 and pp. 750-752.

et al. 1992a) is based on the definition of RS as 'the sum of starch and starch-degradation products that, on average, reach the human large intestine'. The results presented confirm that the values obtained in vitro for the foods tested do reflect the amount of starch that is not completely digested and absorbed in the human small intestine.

This work was supported by the Ministry of Agriculture, Fisheries and Food of the United Kingdom.

\section{REFERENCES}

Cummings, J. H. (1995). Short-chain fatty acids. In Human Colonic Bacteria: Nutritional, Physiological and Pathological Aspects, pp. 101-130 [G. Macfarlane and G. Gibson, editors]. Boca Raton, FL: CRC Press.

Dahlquist, A. \& Borgstrom, B. (1961). Digestion and absorption of disaccharides in man. Biochemical Journal 81, 411-418.

Englyst, H. N. \& Cummings, J. H. (1985). Digestion of the polysaccharides of some cereal foods in the human small intestine. American Journal of Clinical Nutrition 42, 778-787.

Englyst, H. N. \& Cummings, J. H. (1986). Digestion of the carbohydrates of banana (Musa paradisiaca sapientum) in the human small intestine. American Journal of Clinical Nutrition 44, 42-50.

Englyst, H. N. \& Cummings, J. H. (1987). Digestion of the polysaccharides of potato in the small intestine of man. American Journal of Clinical Nutrition 45, 423-431.

Englyst, H. N. \& Kingman, S. M. (1990). Dietary fiber and resistant starch. A nutritional classification of plant polysaccharides. In Dietary Fiber, pp. 49-65 [D. Kritchevsky, C. Bonfield and J. W. Anderson, editors]. New York: Plenum.

Englyst, H. N, Kingman, S. M. \& Cummings, J. H. (1992a). Classification and measurement of nutritionally important starch fractions. European Journal of Clinical Nutrition 46, S33-S50.

Englyst, H. N., Quigley, M. E., Hudson, G. J. \& Cummings, J. H. (1992b). Determination of dietary fibre as nonstarch polysaccharides by gas-liquid chromatography. Analyst 117, 1707-1714.

Englyst, H. N., Wiggins, H. S. \& Cummings, J. H. (1982). Determination of the non-starch polysaccharides in plant foods by gas-liquid chromatography of constituent sugars as alditol acetates. Analyst 107, 307-318.

McNeil, N. I., Bingham, S., Cole, T. J., Grant, A. M. \& Cummings, J. H. (1982). Diet and health of people with an ileostomy. II. Ileostomy function and nutritional state. British Journal of Nutrition 47, 407-415.

Rombeau, J. L., Kripke, S. A. \& Settle, R. G. (1990). Short-chain fatty acids. Production, absorption, metabolism, and intestinal effects. In Dietary Fiber, pp. 317-337 [D. Kritchevsky, C. Bonfield and J. W. Anderson, editors]. New York: Plenum. 